\title{
Definition of Engineering Asset Management: a Review
}

\author{
M. S. Somia Alfatih ${ }^{1, a}$, M. Salman Leong ${ }^{2, b}$ and L.M. Hee \\ ${ }^{1,2}$ Institute of Noise and Vibration,Universiti Teknologi Malaysia, Kuala Lumpur, Malaysia \\ asomia.alfatih@gmail.com, bsalman@ic.utm.my, ${ }^{\mathrm{c}}$ mhlim@ic.utm.my
}

\section{Keywords: Asset Management, Engineering Asset Management.}

\begin{abstract}
The terminology of "Asset Management" (AM) has been widely used in many organizations. It has been generally accepted and defined as a cost effective approach for asset operation, maintenance, upgrade, and disposal. It covers many scopes and topics spanning from financial, IT, human resources, and also physical engineered assets. Engineering asset management (EAM) is the management of engineering assets and it provides guidelines on the effective usage of all the physical engineered assets within the organization. It is deemed essential to understand the concept of effective EAM and practices in an organization. This paper provides a review on the definition and concepts of AM and EAM with the aim of providing good insights and understanding on this topics.
\end{abstract}

\section{Introduction}

Definitions of asset management have wide and a very broad scope, covering a variety of areas including general management, operations and production and, financial and human aspects. There are five different types of assets in any organization ranging from human assets, information assets, financial assets and intangible assets (reputation, morale, intellectual property, goodwill, etc.). The physical assets represent only one of these broad categories of asset types that have to be managed holistically in order to achieve the organizational strategic plan. A physical asset is recognized as any item owned for long term and short term use, in all economic activities for an organization. This asset can be any item within the organization and it can be of tangible or intangible. In the past, the importance of asset management were not properly recognized and applied in many organizations but recently it had become of great value as the physical asset represent an important factor in the whole asset management process. A physical Asset is defined by Amadi-Echendu, (2008) As "an entity that is capable of creating, sustaining or destroying value at any stage in its life-cycle.”[1].

\section{Asset Management}

Asset Management is generally defined as the activities associated with the identification of the needed assets and its financial needs, asset merchandise, maintenance and supply chain and disposal or renewal of these specific assets. The Asset Management Council in Australia defined AM as the management of physical assets life cycle in order to achieve certain outputs and goals in an enterprise [2]. AM is also defined as the coordinated practices where any organization can effectively manage the sustainable level of its assets and its associated performance, risks and expenditures over their lifecycles to achieve the organization plans and goals [3]. As stated in PAS 55, a Publicly Available Specification on Asset Management published by the British Standards Institute Based on these definitions it can be summaries that AM is mainly related to the best practices in any organization to manage its physical asset sustainability through its entire life cycle. The concept of Asset Management has recently gained popularity and being practiced in different fields [4]. Asset management is a wide field and thus it was defined in various different ways. Tywoniak et al. (2008) defined AM as the procedure to deliver a product or service in an optimum way [5]. Davis (2007) provides the definition of AM in the context of engineering Asset Management as the continuous process improvement strategy for improving the availability, safety, reliability and longevity of plant assets, i.e., systems, facilities, equipment and processes [6]. Other reviews of AM can be found in Mitchell [7], Schneider et al.[8], Mathew et. al [9] and many more. 
The main principal objective of asset management is to enable an organization to meet its objectives efficiently and effectively. Effective asset management could be achieved by ensuring that all service potential of assets are appropriately used and maintained, In contrast with this, efficient AM should always seek the continuous upgrade and improvement of asset utilization, performance and feasibility in short term and long term basis. In addition, it can be addressed that managing asset in an organization is mainly concerned by achieving organization's goals at the lowest possible life cycle cost. There also a different range of definitions for asset management in many fields including transportation [10], construction [11], electricity [12] chemical engineering [13] and irrigation [14] [15]. An effective decision making framework could be achieved by conducting asset management plans that incorporates all the organization departments and sectors for long term plans success[10]. The concern of the asset life cycle plans become of great and growing interest in many industries as it generalize asset maintenance practices to whole asset management plans.

\section{Physical Asset Management}

The concept of Physical Asset Management (PAM) has become well known in recent years in many industries and its concepts and practices are spreading fast worldwide [16]. One of the very important reasons behind this is that many organizations and industries found that to achieve the organization goals; one must manage the physical assets effectively and efficiently. It is stated by Mitchell (2007) that it is very important to both maintain and increase the efficiency of any physical asset for maximum production and revenue at same time minimizing operation and capital costs within the organizations [17]. Conflicting requirements need to be balanced and is crucial to achieve effective AM within an organization [18].

PAM had been considered in many industries as part of the maintenance activity in an organization [19]. Maintenance is basically concerned with the continues care to keep the asset under certain limit of operating condition [20].

\section{PAS 55}

The Institute of Asset Management (IAM) with a collaboration with the British Standards Institution (BSI) and various other organizations, had introduced a standard specifications for asset management which is known as Publicly Available Specification 55 (PAS 55), it provides an overview on what needs to be done to manage physical assets for business objectives at any point in its life cycle.

PAS 55 was first published in 2004 and substantially revised in 2008. It has been very widely adopted around the world with great success as a tool for integrating and improving business practices, raising performance and assuring greater consistency and transparency. The main scope of PAS 55 is the management of physical assets, but it can also be used to manage different class of assets. PAS 55 is well recognized, as its core function is to achieve a successful asset management optimal management of physical assets which are also involves managing people, information, finances and other asset classes.

PAS 55 divides into two different sections. The first, PAS 55-1, is the Specification for the optimized management of physical assets. The second, PAS 55-2, is the Guidelines for the application of PAS 55-1. The scope of PAS 55 considers the most important features in an organization with the aim of improving PAM. It also focuses on the interdependency of different asset categories by aligning an organization's strategic plan with its asset management goals. Furthermore, it is clearly indicated that the scope of the PAS 55 primarily focuses on how to achieve successful PAM. It highlights the fact that effective implementation of PAM enables an organization to maximize value and achieve its strategic objectives. 


\section{Engineering Asset Management}

EAM generally refer to the management of the engineering assets such as: equipment, buildings, inventories, etc. Amadi-Echendu et al. (2010) stated that Engineering Asset Management (EAM) requires an information system to capture data that can be used to support decision making [21]. Brunette (2014) highlighted the aspects of engineered assets and stated that EAM is a multidisciplinary approach which includes management, economics and information technology. EAM decisions cover a wide range of disciplines from operational aspects to strategically Aspects [22].

EAM is concerned with the life cycle management of "engineered" physical assets in order to achieve the business objectives for an organization that may own or manage an asset. EAM becomes a vital part of business management for many organizations especially when capital investment in plant equipment or infrastructure is significant and the productivity/sustainability of the asset is crucial to the competitive capability of the business.

Most of the literature of EAM focused on two important aspects: the technology and communication technology required in the management of data relating to assets and the decision making techniques in the management of the engineered assets. EAM concerns the productive use of those assets that provide the value supporting all assets in the economy. It is thus essential to all that it is carried through as effectively as possible.

\section{Condition Monitoring (CM) and EAM}

$\mathrm{CM}$ of an asset is related to the EAM in a way that the data and information investigations are of great importance so the asset can be monitored more effectively to prevent premature deterioration. $\mathrm{CM}$ analysis are effective in managing the equipment and acquire the information for its life cycle plan [23]. Most of the organizations utilize CM technology to identify potential catastrophic failure with the intention to accurately schedule urgent maintenance activity so as to prevent operational interruptions. Consequently, a large number of $\mathrm{CM}$ research has been concerned with the development of algorithms for the diagnosis of fault symptoms of potential failures.

EAM needs accurate assessment and prediction of future asset health condition, and this could be achieved through developing algorithms and models to improve failure prediction, predict probability to failure and its accuracy and improve the equipment reliability and performance rather than detecting faults [24].

\section{Asset Management Strategies}

The successful asset management strategies mainly aim to achieve specific physical asset management activities within given period of time. These strategies are defined as the way and direction of any organization through its configuration of resources within a challenging environment, to meet the needs of markets and to fulfil stakeholder expectations [25]. When compiling a strategy, an assessment of the current state of the organization is required in order to assess its improvement potential. An organization long term plan aligned together with the requirements of maintenance are required to develop a successful management strategy, such a strategy would be applied to the entire organization division and not only the maintenance sector. [6]. PAS 55 defined the physical asset management strategy contest as the plan to achieve sustainable level of asset management for long term to assist the organizational strategic plans [26]. One of the main challenges faced in the process of developing PAM strategy, is to create and maintain a clear line of sight which is very important to achieve successful operations. The strategy should be aligned with the PAM policy and should carry the requirements and objectives, originated in the policy, throughout all organizational levels, down to the very last operator. This shows the importance of such a strategy in strive for excellent operations. It is thus these strategies are of great value to all these activities as long as it is practiced effectively and efficiently. 


\section{Summary}

In order to make the right decisions for managing the physical or engineered asset, it is very important to understand the concept and practices of EAM and have an insight toward applying them to an organization. Most of the definitions of AM conclude that AM is mainly concerned with applying technical and financial judgement practices to decide what assets we need to meet our business aims, and then to acquire and logistically sustaining the assets over their whole life, through to disposal. It is therefore of great value to differentiate between AM activities and other activities in order to maintain high level of operation. By understanding the concept of EAM and applying the best practices in all levels of the organization, all asset managers can actively develop their organizations in a way that the long term as well as the short term goals could be achieved.

\section{Acknowledgment}

This work is supported by the UTM Flagship Grant (Q.K130000.2409.01G44) and Research University Grant of UTM (Q.K130000.2540.06H51 and Q.J130000.2524.05H01) financed by the Ministry of Education, Malaysia.

It is also acknowledged that the main author is sponsored for study from the Ministry of higher Education -Malaysia under MTCP Scholarship.

\section{References}

[1] Amadi-Echendu, J. Managing physical assets is a paradigm shift from maintenance. in Engineering Management Conference, 2004. Proceedings. 2004 IEEE International. 2004. IEEE.

[2] Shah, A. and A. Kumar, Review on Australian and international practices for asset management in building infrastructure. 2003.

[3] PAS 55-1 and PAS 55-2 Asset Management, British Standards Institution, www.bsiglobal.com.

[4] Hastings, N.A.J., Physical asset management. 2009: Springer.

[5] Tywoniak, S., et al., Towards an integrated perspective on fleet asset management: engineering and governance considerations. 2008.

[6] Davis, J., What is asset management and where do you start? Journal American Water Works Association, 2007. 99(10): p. 26.

[7] Al-Tarawneh, H.A., The Main Factors beyond Decision Making. Journal of Management Research, 2012. 4(1).

[8] Schneider, J., et al., Asset management techniques. International Journal of Electrical Power \& Energy Systems, 2006. 28(9): p. 643-654.

[9] Mathew, J., et al., Engineering Asset Management and Infrastructure Sustainability.

[10] McElroy, R.S. Update on national asset management initiatives: facilitating investment decision-making. in Innovations in Urban Infrastructure Seminar of the APWA International Public Works Congress. 1999. Citeseer.

[11] Vanier, D.D., Why industry needs asset management tools. Journal of computing in civil engineering, 2001. 15(1): p. 35-43.

[12] Morton, K., Asset management in the electricity supply industry. Power Engineering Journal, 1999. 13(5): p. 233-240.

[13] Chopey, N. and J. Fisher-Rosemount, Put a Smart Face on Asset Management; Intelligent field devices can make plant maintenance more effective, less costly. Chemical Engineering, 1999. 106(2): p. 108.

[14] Malano, H.M., N.V. Chien, and H.N. Turral, Asset management for irrigation and drainage infrastructure-principles and case study. Irrigation and Drainage systems, 1999. 13(2): p. 109129. 
[15] Malano, H.M., B.A. George, and B. Davidson, Asset management modelling framework for irrigation and drainage systems: Principles and case study application. Irrigation and drainage systems, 2005. 19(2): p. 107-127.

[16] Frolov, V., et al., Identifying core functions of asset management, in Definitions, Concepts and Scope of Engineering Asset Management. 2010, Springer. p. 19-30.

[17] Mitchell, J.S., J.E. Hickman, and J.E. Amadi-Echendu, Physical asset management handbook. 2007: Clarion technical publishers.

[18] Mitchell, J.S., Physical Asset Managment Handbook. . Clarion Technical Publishers, 2002. 3(3rd edition).

[19] Myburg, J., Physical asset management system concepts. 2007.

[20] Ben-Daya, M., Duffuaa S, O, Abdul Raouf, Jezdimir K. ,Ait-Kadi. D., Handbook of Maintenance Management and Engineering, chap. 4 Failure Mode and Effect Analysis. Springer. 75(89).

[21] Amadi-Echendu, J.E., et al., What is engineering asset management? 2010: Springer.

[22] Burnett, S. and P. Vlok, A simplified numerical decision-making methodology for physical asset management decisions. South African Journal of Industrial Engineering, 2014. 25(1): p. 162-175.

[23] Madu, C.N., Competing through maintenance strategies. International Journal of Quality \& Reliability Management, 2000. 17(9): p. 937-949.

[24] Ma, L., Condition monitoring in engineering asset management. 2007.

[25] Scholes, K., G. Johnson, and V. Ambrosini, Exploring techniques of analysis and evaluation in strategic management. 1998: Pearson Higher Education.

[26] Group, U., Europe (2005), PAS 55 Publicly Available Specification published by the BSI. Europe. 